ARTIFICIAL SATELLITES, Vol. 47, No. $4-2012$
DOI: $10.2478 / v 10018-012-0019-5$

\title{
STUDY OF EGNOS SAFETY OF LIFE SERVICE DURING THE PERIOD OF SOLAR MAXIMUM ACTIVITY
}

\author{
Marek Grzegorzewski, Anna Swiatek* \\ Stanislaw Oszczak, Adam Ciecko, Janusz Cwiklak \\ Polish Air Force Academy, Deblin, Poland \\ * Space Research Centre PAS, Warsaw \\ marekgrzegorzewski@wp.pl, ana@.cbk.waw.pl, \\ oszczak@uni.olsztyn.pl, a.ciecko@kgsin.pl,jcwiklak@wp.pl
}

\begin{abstract}
The Satellite Base Augmentation System (SBAS) - EGNOS (European Geostationary Navigation Overlay Service) has been certified for Safety of Life (SoL) service for aircraft navigation since $2^{\text {nd }}$ of March 2011. Unfortunately for the territory of Poland, located at the edge of EGNOS service area, the quality of the service corrections are still not sufficient for aircraft navigation requirements. Years 2012 and 2013 are forecasted as a maximum of solar activity in a 11-year solar cycle. This time period will be the chance to perform the first tests for the EGNOS Safety of Life service quality in disturbed ionospheric conditions. During the previous maximum of solar activity, the storm on 30 October 2003 resulted in the inability to use WAAS corrections for more than 12 hours. This was caused by a very large gradient of disturbances and its' very sharp boundaries - vertical TEC (VTEC) varied from $\sim 40$ to $\sim 120$ TECU (TEC units) within an hour (over $\sim 150 \mathrm{~km}$ distance). These circumstances gave the opportunity to carry out the test flights to examine the navigation parameters obtained for EGNOS SoL service in disturbed ionospheric conditions. The paper presents project proposal of study and analyses of such fundamental navigation parameters as: accuracy of determined position, availability, continuity and integrity, determined for selected disturbances in relation to quiet conditions. It can give a possibility to estimate of the quality of EGNOS SoL service in Polish airspace during the different phases of flight and its resistance to critical ionospheric conditions.
\end{abstract}

Keywords: GPS, GNSS, EGNOS, ionospheric corrections

\section{INTRODUCTION}

The European Geostationary Navigation Overlay Service (EGNOS) was created as Europe's first activity in the field of Global Navigation Satellite Systems (GNSS). European Space Base Augmentation System (SBAS) consists of three geostationary satellites and a network of ground stations. EGNOS achieves its' aim by transmitting a signal containing information on the reliability and accuracy of the positioning signals sent out by GPS. Officially it allows users in Europe and beyond to determine their position to within 1.5 metres. Unfortunately, in Poland, lying on the edge of the range of EGNOS corrections, the situation is not as good as the official information proclaim. Since 1 October 2009 the EGNOS Open Service has been available and Safety of Life service has been officially declared available for aviation on 2 
March 2011. The quality of the service corrections on the territory of Poland is still not sufficient for aircraft navigation requirements. The work of EGNOS in operational mode and all archived EGNOS correction data in EMS files are related to the quiet period - the minimum of solar cycle. For that reason all tests presented in the paper, prepared for system, gave the results obtained from measurements taken during the best possible conditions. The theoretical analyses could give the background to the future tests, prepared for more disturbed conditions.

\section{FLY TESTS IN POLAND}

An information on the upcoming release of Safety-of-Life service for aviation resulted in the preparation of test flights in 2010 . The Figure 1 shows the theoretical positioning accuracy in vertical component using the Safety-of-Life service presented in (Safety of Life Service Definition Document, 2011).

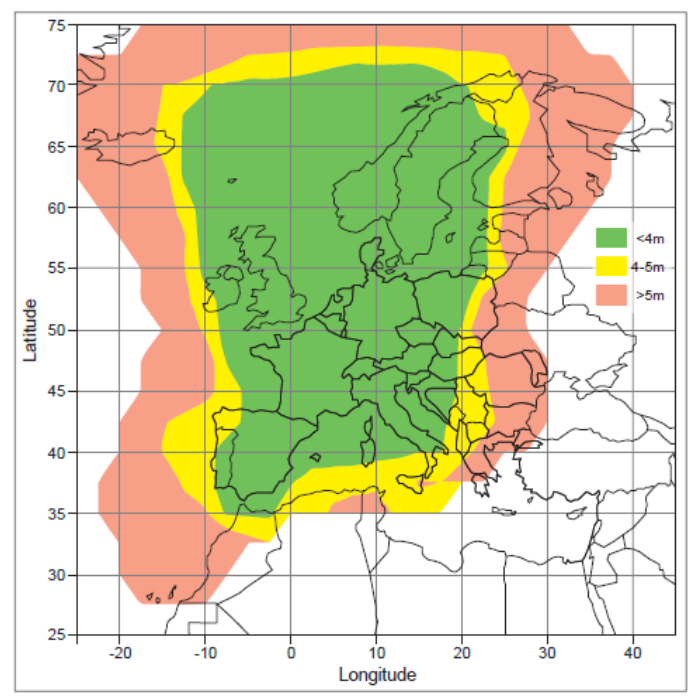

Fig. 1. The expected positioning accuracy using the SoL service, published in Safety of Life Service Definition Document

In order to perform the analyses of EGNOS system in Poland test flights were organized for $26^{\text {th }}$ July 2010 in Deblin and $10^{\text {th }}$ September 2010 in Chelm (Grunwald et. al., 2011). Two kinds of receivers were used for measurements. Precise geodetic receivers used were as follows: Topcon HiperPro and Javad Alpha and two navigation receivers Thales MobileMapper. Selected equipment was tested to work in real time and in post-processing mode. Reference positions for the coordinates of points on trajectories were calculated at the post-processing mode based on observations from the physical and virtual reference station ASG-EUPOS. Thus the coordinates of reference points were determined with centimetre accuracy and were accepted as "true" for those experiments. The accuracies of position presented below represent the coordinates' differences between references one and appointed in navigation mode during flights.

For $26^{\text {th }}$ July 2010 in the vicinity of the airport Deblin (belonging to the Polish Air Force Academy) two test flights were held with the Cessna 172 RG. The flight 1 was held from 10:00 - 11:00 (GPS time), while flight 2 was held between 11:22 - 12:03 (GPS time). Figure 2 shows the recorded flight trajectories for both flights. The geomagnetic and ionospheric conditions were quiet - on the base of PRIME recommendations (Bradley P. A. 1995) for that time so the EGNOS ionospheric correction should be determined in accordance with actual conditions and with relatively small errors. 


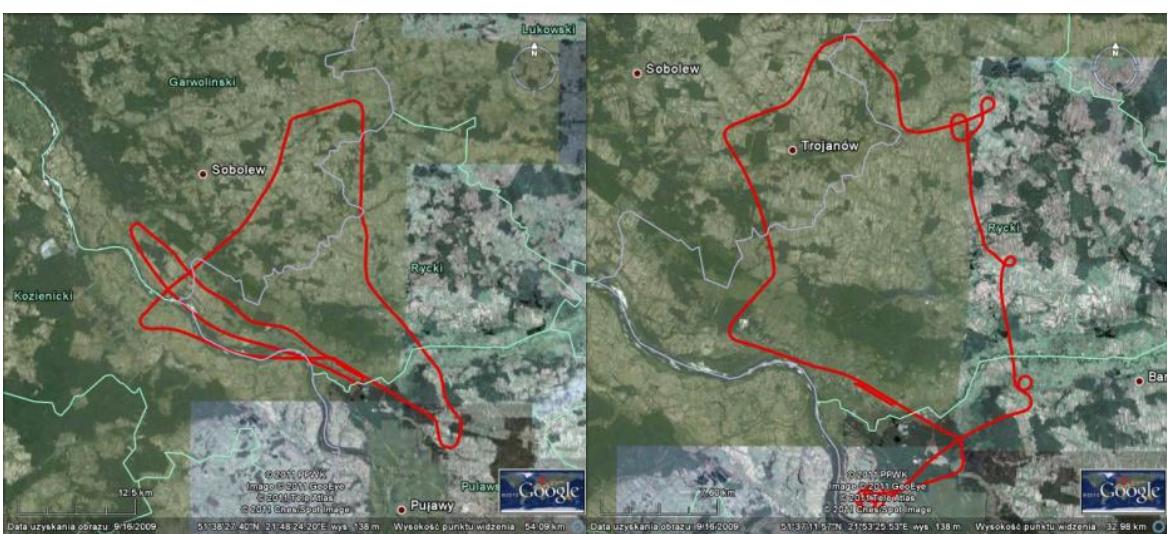

Fig. 2. Recorded trajectories of flight 1 (left) and 2 (right) performed on $26^{\text {th }}$ July 2010

The EGNOS corrections for computations were obtained using the Internet service EMS (EGNOS Message Server) archiving information that is transmitted from the EGNOS geostationary satellites to users in real time. Computations were performed in the "open source" software - RTKlib 2.4.0 with the same configuration for all calculations (with elevation mask $15^{\circ}$ ). The EGNOS positioning accuracy was estimated in post-processing mode by comparison with the reference positions and results of standalone GPS mode. The results from flight 1 and flight 2 can be compared in Figures 3-8.

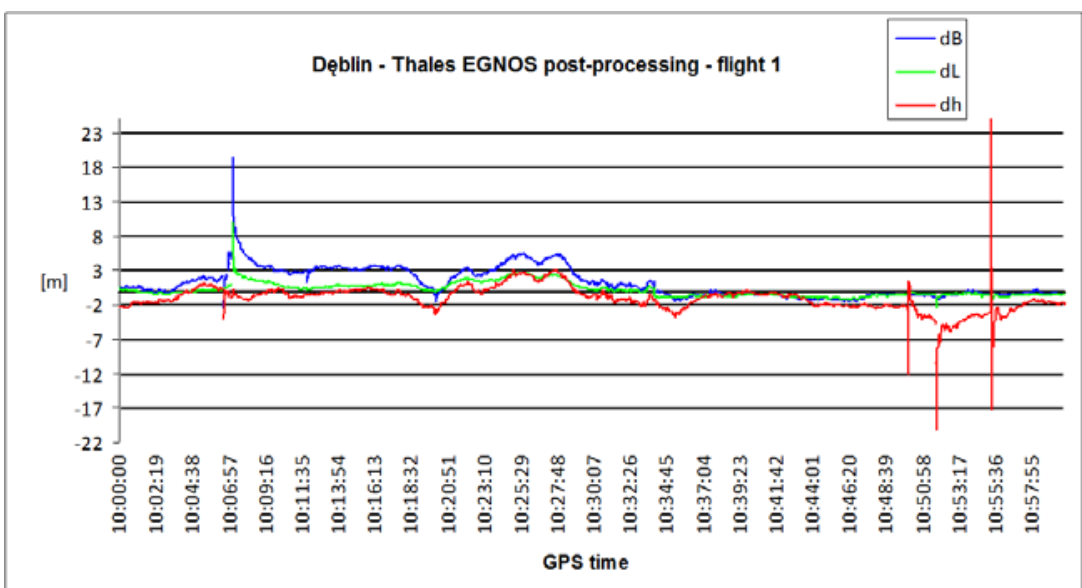

Fig. 3. Position differences between reference and appointed with EGNOS corrections in the post-processing mode, for Thales MobileMapper navigation receiver (flight 1).

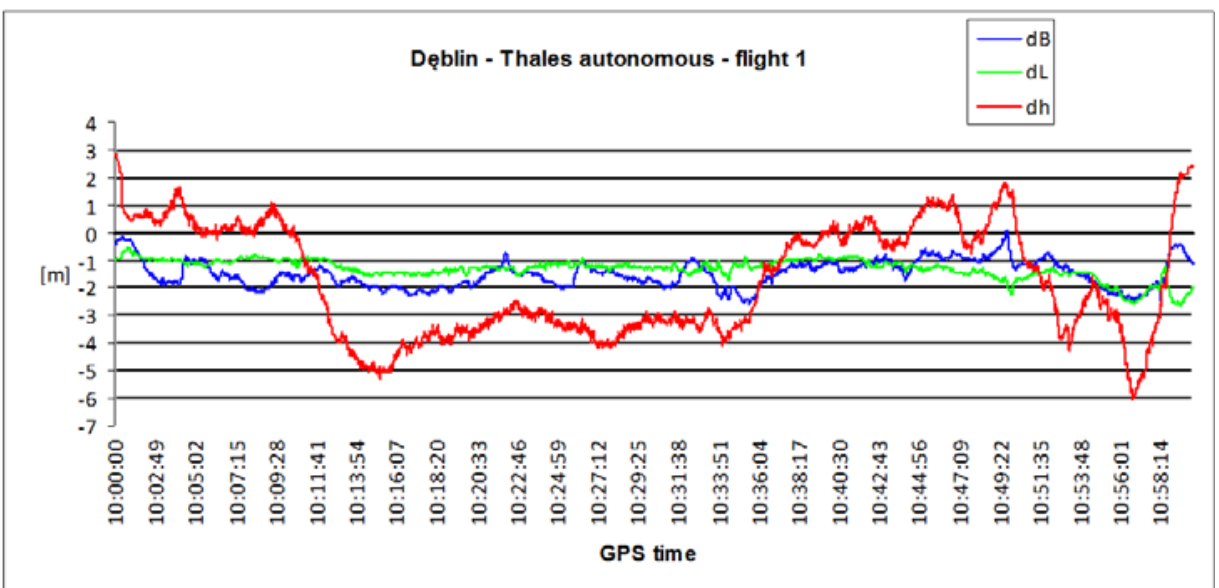

Fig. 4. Position differences between reference and appointed in real time for standalone mode, for Thales MobileMapper navigation receiver (flight 1). 


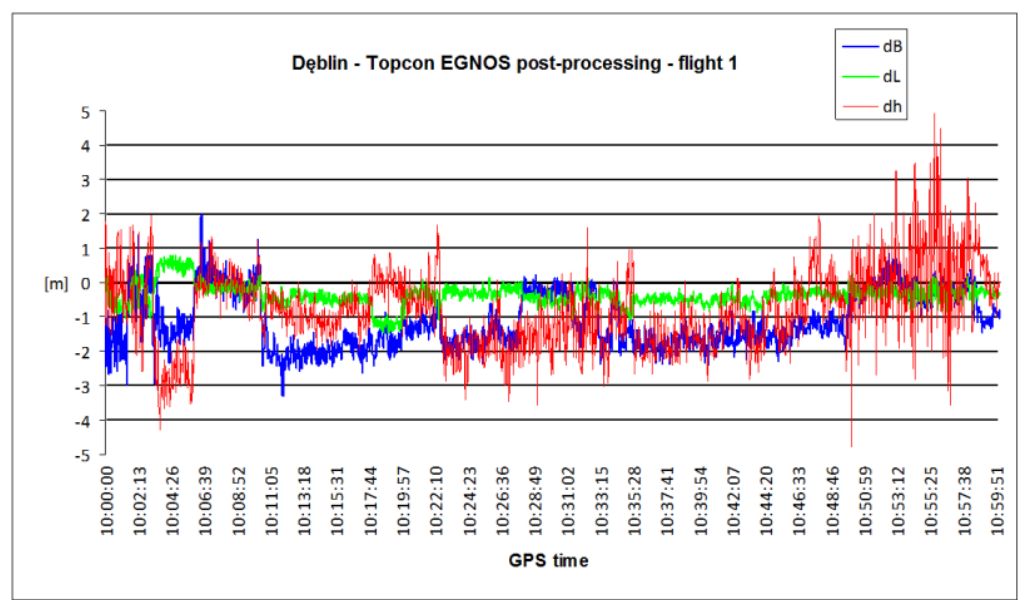

Fig. 5. Position differences between reference and appointed with EGNOS corrections in the post-processing mode, for Topcon HiperPro geodetic receiver (flight 1).

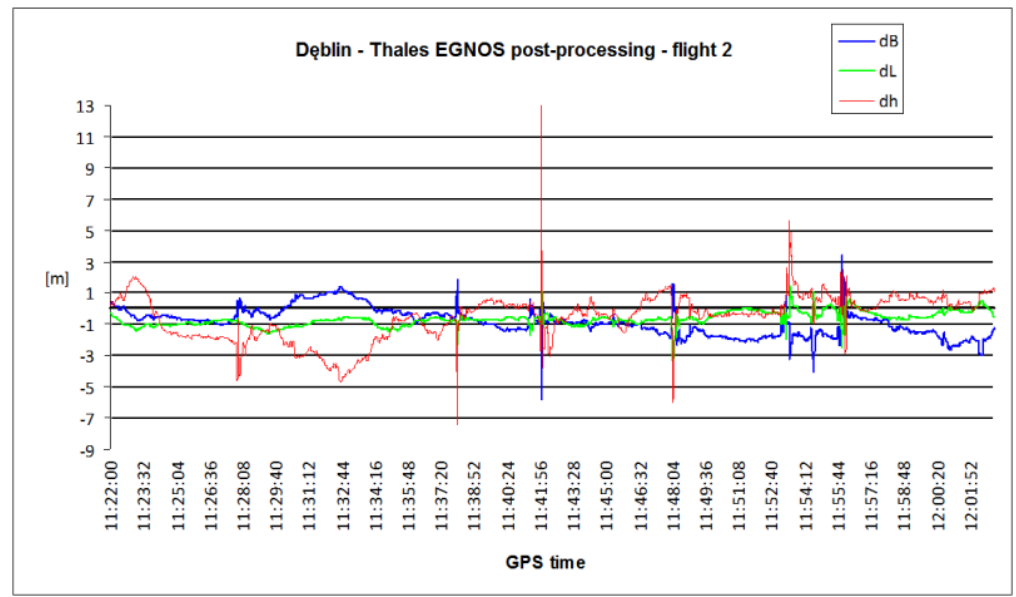

Fig. 6. Position differences between reference and appointed with EGNOS corrections in the post-processing mode, for Thales MobileMapper navigation receiver (flight 2).

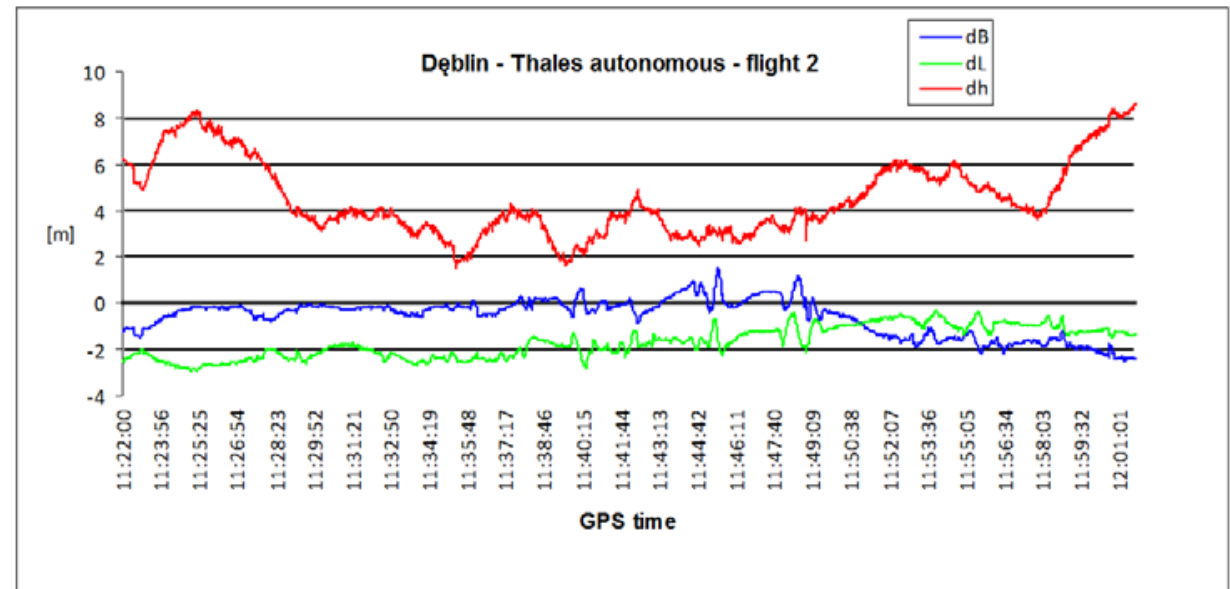

Fig. 7. Position differences between reference and appointed in real time for standalone mode, for Thales MobileMapper navigation receiver (flight 2). 




Fig. 8. Position differences between reference and appointed with EGNOS corrections in the post-processing mode, for Topcon HiperPro geodetic receiver (flight 2).

Based on these results from the flight 1 and flight 2 it can be concluded that the results obtained from testing the Thales MobileMapper receiver (positioning accuracy decrease at times to several meters) are worse than those obtained using geodetic receiver Topcon HiperPro. This may be related to different technological solutions of different classes of receivers. It should be noticed that the results of the autonomous standalone positioning in real time using a Thales Mobile Mapper receiver, especially horizontal accuracy results are comparable to those obtained using a Topcon receiver HiperPro with EGNOS in postprocessing mode. On $10^{\text {th }}$ September 2010 at the airport owned by the State School of Higher Education in Chelm experimental flight was held with the Cessna 152 II between 11:35 11:57 (GPS time). As in the previous case the same type of receivers and software with the same configuration for all calculations were used (with elevation mask $15^{\circ}$ ). Obtained results are presented in Figures 9-12.



Fig. 9. Position differences between reference and appointed with EGNOS corrections in the post-processing mode, for Thales MobileMapper navigation receiver (flight in vicinity of Chelm city) 


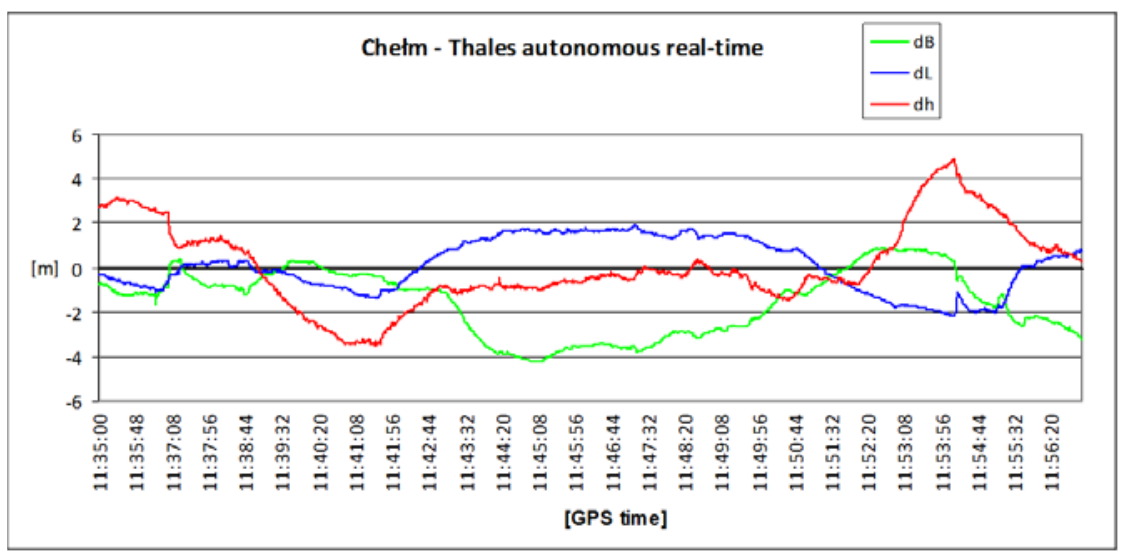

Fig. 10. Position differences between reference and appointed in real time for standalone mode, for Thales MobileMapper navigation receiver (flight in vicinity of Chelm city)

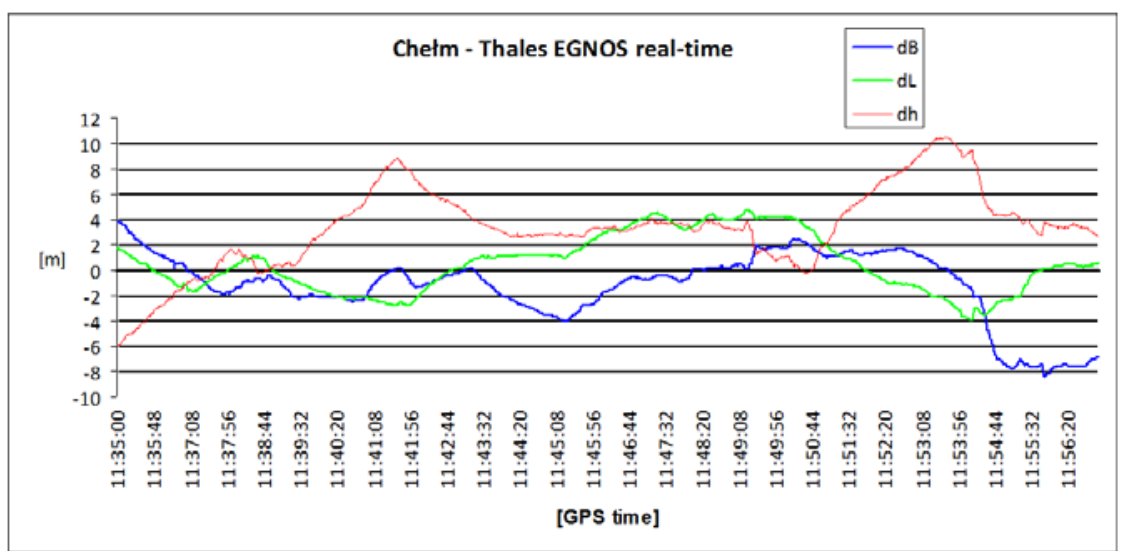

Fig. 11. Position differences between reference and appointed with EGNOS corrections in real time, for Thales MobileMapper navigation receiver (flight in vicinity of Chelm city)

Analysing the results of the EGNOS positioning post-processing mode, it can be noticed that most of the raw observations recorded by the receiver have not received corrections to the pseudorange of the right quality. Test results for the EGNOS positioning in real time are characterized by the availability of service throughout the flight, but the characteristics of the accuracy of these results indicate a high positioning errors (worse than in the autonomous positioning). This may be caused by the lack of RIMS stations east of Warsaw, and therefore EGNOS corrections are not transmitted to the satellites being tracked over the area.

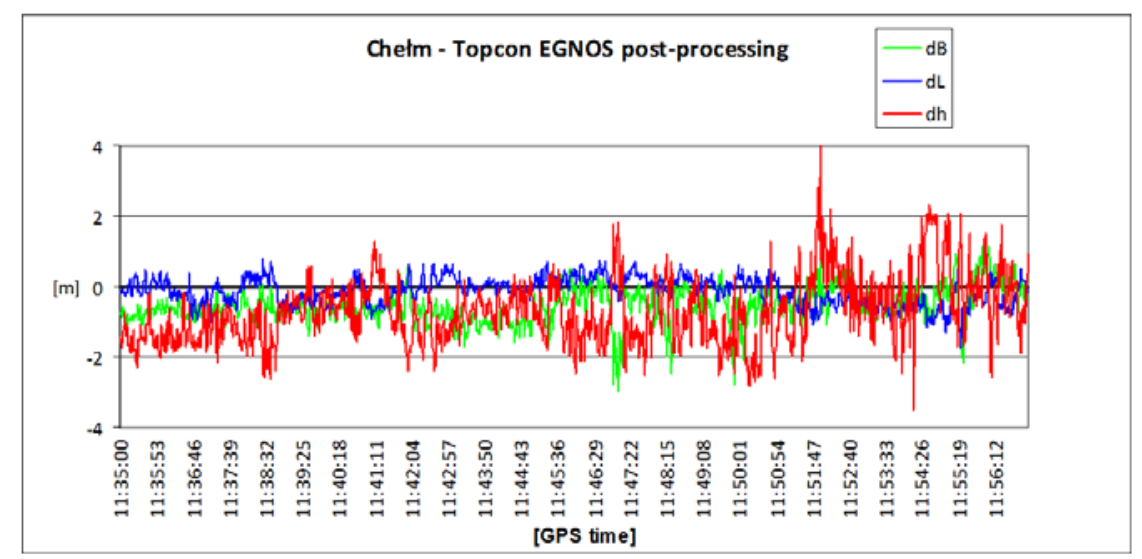

Fig. 12. Position differences between reference and appointed with EGNOS corrections in the post-processing mode, for Topcon HiperPro geodetic receiver (flight in vicinity of Chelm) 


\section{IONOSPHERIC CONDITIONS}

The part of EGNOS correction consists of the information about the ionospheric delay of GNSS signal expressed in meters together with the errors of those values. The inospheric corrections are computed for grid defined in EGNOS. Under conditions for which correction cannot be determined, or for which correction is determined with a large error, error value 15 applies, which means: do not use.

During the severe ionospheric storm it is possible the system stops the availability of usability of ionospheric correction. Such the case was in America where, during a strong ionospheric storm in $30^{\text {th }}$ October 2003, the WAAS corrections had the status of denied availability for more than 12 hours. The figure 13 shows the graphs presented by Haddad O. and S. Skone, in 2010 (Haddad and Skone, 2010) on TECTERRA Workshop describing problem with WAAS correction in $30^{\text {th }}$ October 2003.

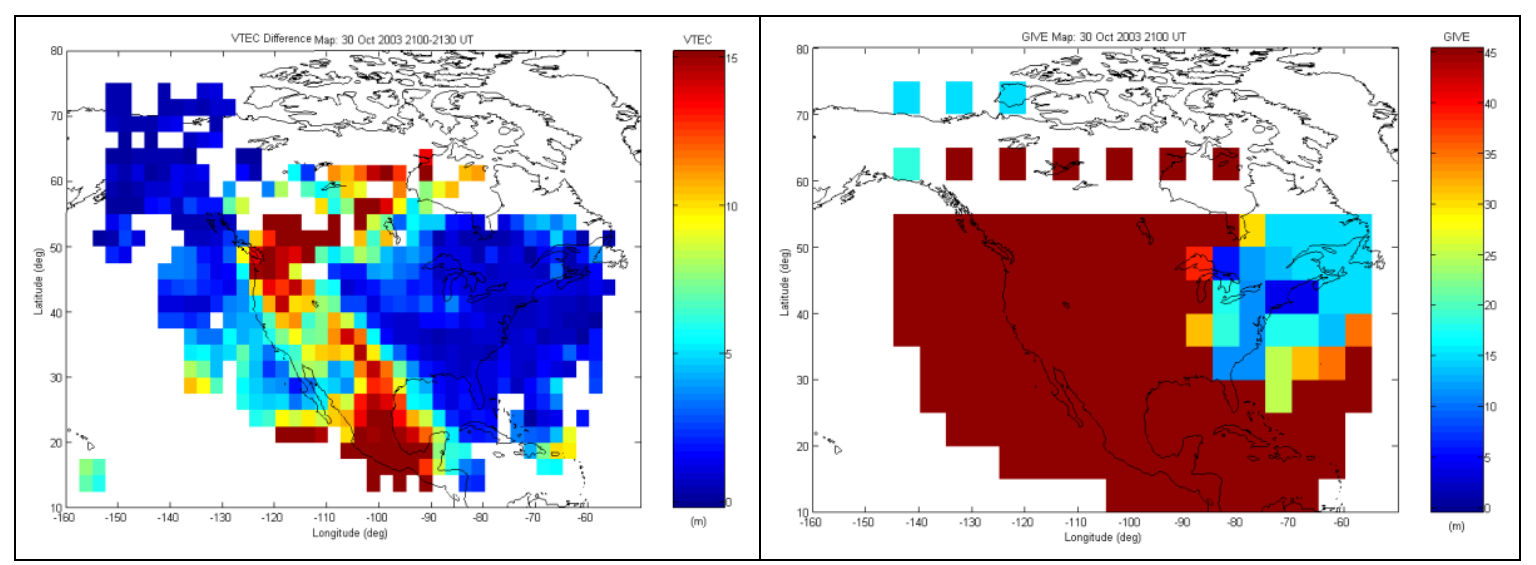

Fig. 13. The values of VTEC (left) and GIVE (right) obtained for WAAS for severe ionospheric storm of $30^{\text {th }}$ October 2003.

The strong solar flare could generate the sudden ionospheric disturbance. The high gradient of TEC in short time and distance could cause the calculated ionospheric corrections to become unsuitable for the area covered by such a sharp change in the TEC. As the example of sudden ionospheric disturbance the case occurred in Europe on $28^{\text {th }}$ October 2003 could be used. That day the extremely strong solar flare class occurred from solar region number 486 located at solar disc: S16, E08. The flare targeted almost directly toward the Earth with extremely strong $\mathrm{X}$-ray radiation (X17.2) and optical (4B) with strong radio (490000 sfu on $245 \mathrm{MHz}$ and $13000 \mathrm{sfu}$ for $10 \mathrm{~cm}$ wave) and full halo CME with speed about $2000 \mathrm{~km} / \mathrm{s}$ and proton events for $>10 \mathrm{MeV}$ and $>100 \mathrm{MeV}$ caused the abrupt increase in TEC values. The analyses of selected (see Table 1) GNSS stations over Europe shows that during the single minutes TEC increased by more than 15 TECU (TEC units). The figure 14 shows the increase of vertical TEC observed satellite PRN 7 selected as the example of that case.

Table 1. Geodetic coordinates of selected GNSS European stations observed the sudden Ionospherc disturbance in $28^{\text {th }}$ October 2003.

\begin{tabular}{|l|l|l|l|}
\hline Station & Name & Latitude & Longitude \\
\hline Sodankyla & SODA & $67.42^{\circ} \mathrm{N}$ & $26.39^{\circ} \mathrm{E}$ \\
\hline Klobuck & KLOB & $50.91^{\circ} \mathrm{N}$ & $18.94^{\circ} \mathrm{E}$ \\
\hline Kiev & GLSV & $50.36^{\circ} \mathrm{N}$ & $30.50^{\circ} \mathrm{E}$ \\
\hline Villafranca & VILL & $40.44^{\circ} \mathrm{N}$ & $3.95^{\circ} \mathrm{W}$ \\
\hline Matera & MATE & $40.65^{\circ} \mathrm{N}$ & $16.70^{\circ} \mathrm{E}$ \\
\hline Ankara & ANKR & $39.89^{\circ} \mathrm{N}$ & $32.76^{\circ} \mathrm{E}$ \\
\hline
\end{tabular}




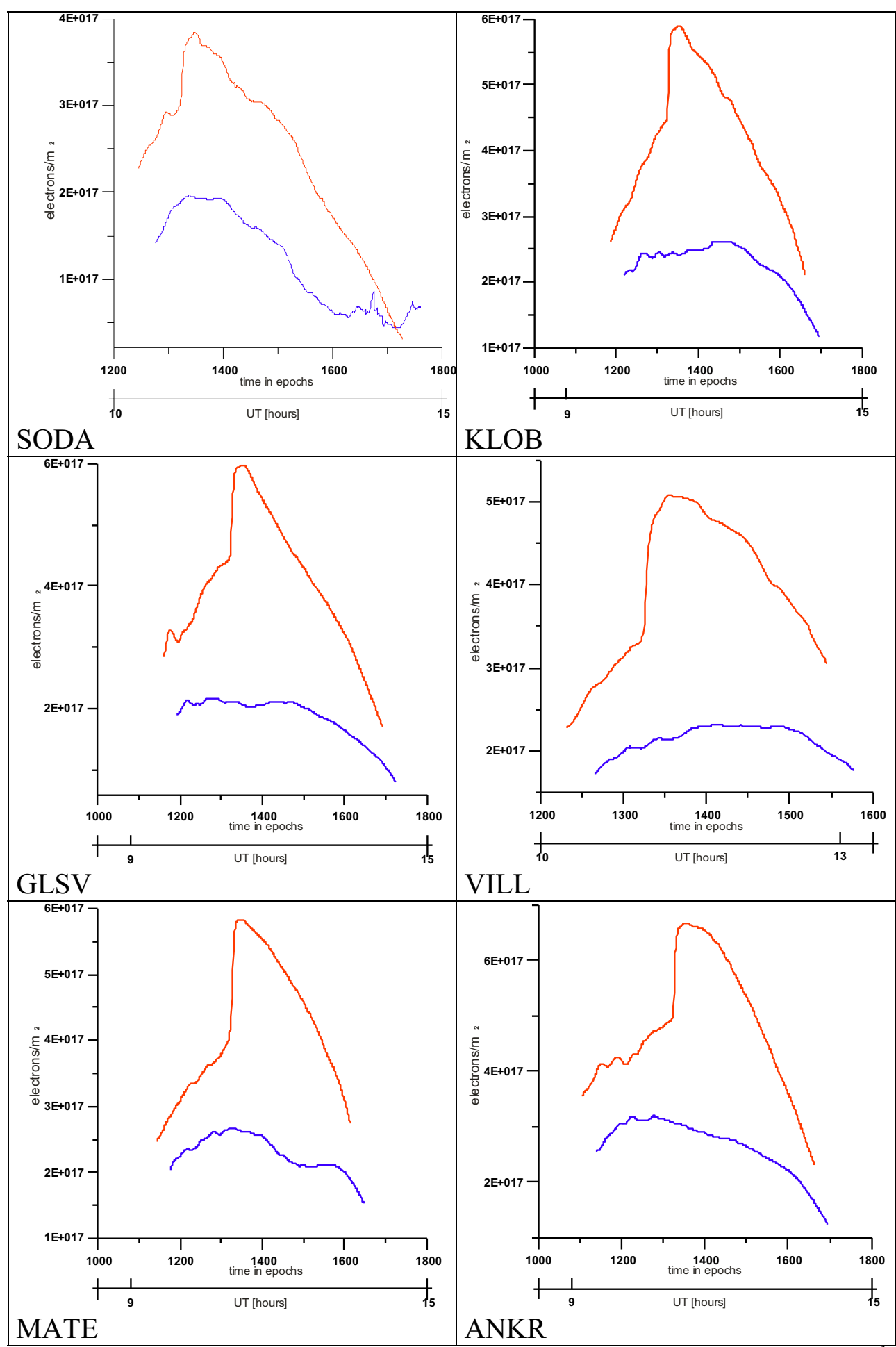

Fig. 14. Sudden increase of vertical TEC value observed for satellite PRN 7, for $28^{\text {th }}$ October 2003 for selected GNSS stations in Europe (red), as a reference values (blue) are presented changes in TEC for $24^{\text {th }}$ October 2003 (ionospheric quiet day).

The case like that is extremely dangerous for fast-moving aircraft. The corrections received at the vehicle do not match the actual conditions and may worsen the obtained position. 


\section{CONCLUSIONS}

Presented results of the fly tests and analyses of ionospheric conditions caused by strong solar flare can open discussion of possible influences of ionospheric disturbances for EGNOS corrections. It becomes particularly important in the current phase of solar cycle. Increasing solar activity creates conditions for new tests of EGNOS. The insuficiently accurate ionospheric corrections for territory of Poland could be a special source of positioning errors especially during disturbed ionospheric conditions. The project proposed by us could answer the question on the relation between the amount of ionospheric disturbance and the positioning error of an aircraft.

\section{REFERENCES}

Bradley P. A. (1995), PRIME (Prediction and Retrospective Ionospheric Modelling over Europe), Final Report, Commission of the European Communities, ECSC-EEC-EAEC, Brussels,

Grunwald G., A. Ciecko, S. Oszczak, R. Kazmierczak, M. Grzegorzewski, J. Cwiklak, (2011)Wykorzystanie systemu EGNOS $w$ monitoringu statków powietrznych $w$ aspekcie uruchomienia serwisu Safety-Of-Life, Aparatura Badawcza i Dydaktyczna - kwartalnik tom XVI Nr 3 (2011), ISSN 1426-9600, s. 133-142

Haddad O., S. Skone, (2010) Wide Area Augmentation System - Limitations and Validation for Canadian Aviation, Presentation on TECTERRA Workshop at Aviation Alberta 7-th Conference, Kananaskis, Alberta October 13, 2010

Safety of Life Service Definition Document, (2011), European Commission DirectorateGeneral for Enterprise and Industry, s. 23-33

Received: 2012-06-21,

Reviewed: 2012-08-28, by C. Specht,

Accepted: 2012-10-12. 